\title{
PENGOLAHAN LIMBAH CAIR PABRIK KELAPA SAWIT (Studi Kasus pada PT. Tri Bakti Sarimas PKS 2 Ibul, Riau)
}

\author{
Melisa $^{*(1)}$, dan Mulono Apriyanto ${ }^{(2)}$ \\ ${ }^{(1)}$ Mahasiswa Teknologi Pangan Universitas Islam Indragiri \\ ${ }^{(2)}$ Dosen Teknologi Pangan Universitas Islam Indragiri \\ * smeli1476@gmail.com
}

\begin{abstract}
Abstrak
Proses produksi pengolahan tandan segar sawit menjadi minyak sawit (Crude Palm Oil) menghasilkan limbah yang cukup banyak, baik dari limbah cair maupun limbah padat. Limbah tersebut berpotensi merusak lingkungan perairan. PT. Tri Bakti Sarimas PKS 2 Ibul merupakan salah satu perusahaan kelapa sawit yang terdapat di Provinsi Riau. Pengolahan limbah cair pada PT. Tri Bakti Sarimas PKS 2 Ibul menggunakan 10 kolam sebagai medianya. Setiap kolam memiliki fungsi yeng berbeda-beda. Limbah yang keluar dari Apolo Tank pertama kali dialirkan ke kolam nomor 1, di kolam ini limbah cair didinginkan kemudian dialirkan ke kolam 2, 3, 4, dan 5, secara berurutan. Pada kolam 2, 3, 4, dan 5, limbah diproses secara anaerob untuk menurunkan kadar BOD. Setelah dari kolam 5, limbah dipompakan ke dalam kolam 6 untuk proses fakultatif yang bertujuan untuk menurunkan BOD dan COD. Setelah itu, limbah dipompakan ke kolam 7, 8, dan 9 secara berurutan. Pada kolam 7 , 8, dan 9, limbah diproses secara aerob yang bertujuan untuk mengubah limbah menjadi stabil dan tidak memberikan dampak pencemaran lingkungan. Kemudian limbah dipompakan ke kolam 10 untuk diendapkan kotorannya sebelum dibuang ke perairan bebas. Hasil pengujian laboratorium, didapatkan kadar COD dan BOD pada PT. Tri Bakti Sarimas PKS 2 Ibul, masing-masing 319 mg/L dan 43 mg/L. Hasil ini telah memenuhi syarat baku mutu limbah cair yang terdapat pada Peraturan Menteri Lingkungan Hidup Republik Indonesia Nomor 5 Tahun 2014.
\end{abstract}

Kata Kunci : limbah kelapa sawit, BOD, COD

\section{PENDAHULUAN}

Kelapa sawit (Elaeis guineensis Jacq.) adalah salah satu sumber minyak nabati. Perkebunan kelapa sawit di Indonesia saat ini berkembang di 24 provinsi. Luas perkebunan kelapa sawit dari tahun ke tahun terus meningkat. Total area kelapa sawit pada tahun 2019 mencapai 14.724 .600 ha. Luas perkebunan rakyat mencapai 6.035 .700 ha atau $41 \%$ dari total area. Bertambahnya area perkebunan sawit, juga menyebabkan meningkatnya produksi kelapa sawit itu sendiri. Produksi kelapa sawit pada tahun 2019 sebesar 45.859.200 ton, yang 35\%-nya merupakan hasil produksi dari perkebunan rakyat (BPS, 2020).

Tanaman kelapa sawit mempunyai banyak kegunaan. Hasilnya banyak 
digunakan pada industri pangan, biodiesel, kosmetik, tekstil, dan farmasi. Komoditas kelapa sawit merupakan salah satu andalan komodi di pertaian selain dari kelapa dan karet. Minyak sawit Indonesia memiliki kontribusi dalam pasar Internasional. Pada tahun 2016, peranan produksi minyak sawit Indonesia mencapai 32\% dari minyak sawit dunia (Azhari, 2018).

PT. Tri Bakti Sarimas PKS 2 Ibul merupakan sebuah perusahaan yang bergerak diberbagai macam bisnis. Perusahaan ini berlokasi di perbatasan antara Kabupaten Kuantan Singingi (Provinsi Riau) dengan Provinsi Sumatera Barat. Pada tahun awal 1990an mulanya perusahaan ini memiliki bisnis inti perkebunan kelapa sawit, kemudian perusaan ini mengembangkan sayapnya dengan menanam kelapa dan kakao. Kemudian hasil panen kelapa di suling menjadi santan siap saji dengan merek dagang Kara.

Dari kegiatan mengolah kelapa sawit, PT. Tri Bakti Sarimas PKS 2 Ibul menghasilkan produk samping, yakni limbah yang dapat mencemari lingkungan jika tidak ditangani dengan baik. Limbah pabrik berasal dari sisa proses pengolahan dari tandan buah segar. Limbah tersebut terbagi menjadi dua jenis yaitu limbah cair dan limbah padat. Limbah padat berasal dari bahan padat, seperti sabut, cangkang, dan janjang kosong. Rata-rata janjang kosong kelapa sawit adalah sekitar 20\% sampai 35\% dari total tandan buah segar yang diproses. Banyaknya volume limbah tersebut, akan dapat mencemari lingkungan. Limbah cair berasal dari bahan cair, seperti condensat perebusan, dan larutan calsium carbonate.

\section{METODOLOGI}

Penelitian dilakukan di PT. Tri Bakti Sarimas PKS 2 Ibul pada bulan
Januari sampai Februari 2020. Penelitian dilakukan dengan cara pengamatan dan wawancara langsung dengan karyawan PT. Tri Bakti Sarimas PKS 2 Ibul. Pengamatan dan wawancara dilakukan untuk mengetahui proses pengolahan limbah cair kelapa sawit yang dihasilkan oleh PT. Tri Bakti Sarimas PKS 2 Ibul. Selain pengamatan di kolam pengolahan limbah, pengamatan juga dilakukan di Laboratorium untuk melihat proses pengujian kandungan $\mathrm{COD}$ dan $\mathrm{BOD}$ limbah cair.

\section{HASIL DAN PEMBAHASAN}

Efek samping dari proses pengolahan kelapa sawit tandan buah segar yakni limbah. Limbah yang dihasilkan terbagi menjadi dua macam, yakni limbah padat dan limbah cair. Limbah cair yang dihasilkan dari pengolahan berupa air dan sludge. Jumlah air buangan tergantung pada sistem pengolahan, kapasitas olah, dan keadaan peralatan klarifikasi. Di PKS 2 stasiun yang menghasilkan limbah cair yakni stasiun klarifikasi dan di stasiun kernel. Di stasiun perebusan juga menghasilkan limbah cair yakni condensate. Limbah padat berasal dari pengolahan berupa janjang kosong, fiber, dan cangkang.

\section{Kolam Pengolahan Limbah Cair}

Pada pengolahan limbah cair, perusahaan menggunakan 10 kolam sebagai medianya. Setiap kolam memiliki fungsi yeng berbeda-beda. Limbah cair yang keluar dari Apolo Tank, mula-mula dibuang ke kolam nomor satu (1). Di kolam 1, limbah cair didinginkan kemudian dialirkan ke kolam 2, 3, 4, dan 5 secara berurutan. Pada kolam 2, 3, 4, dan 5, limbah diproses secara anaerob yang bertujuan 
untuk mengelola limbah dengan mikroorganisme dan menurunkan BOD. Setelah dari kolam 5, limbah dipompakan ke dalam kolam 6 untuk proses fakultatif. Tujuan proses fakultatif adalah untuk menurunkan BOD dan COD.

\section{BOD (Biochemical Oxygen} Demand) merupakan suatu sifat atau karakteristik yang menunjukkan jumlah oksigen terlarut, atau ukuran relatif jumlah oksigen. Oksigen tersebut adalah oksigen yang diperlukan oleh mikroorganisme (bakteri) untuk mengoksidasi atau mendekomposisi bahan organik dalam kondsi aerobic. COD atau Chemical Oxygen Demand merupakan jumlah oksigen yang dibutuhkan untuk mengurai seluruh bahan organik yang terkandung dalam air (Umaly, 1988; Rachmawati, 2017; Nuraini et al.,2019). Nilai BOD atau COD yang diperbolehkan tertuang dalam baku mutu air limbah. Baku mutu air limbah bagi usaha dan/atau kegiatan industri minyak sawit dapat dilihat pada Tabel 1.

Tabel 1. Baku Mutu Air Limbah Industri Minyak Sawit

\begin{tabular}{|l|c|c|}
\hline \multicolumn{1}{|c|}{ Parameter } & $\begin{array}{c}\text { Kadar Paling Tinggi } \\
(\mathrm{mg} / \mathrm{L})\end{array}$ & $\begin{array}{c}\text { Beban Pencemaran } \\
\text { Paling Tinggi (kg/ton) }\end{array}$ \\
\hline BOD & 100 & 0,25 \\
\hline COD & 350 & 0,88 \\
\hline TSS & 250 & 0,63 \\
\hline Minyak dan Lemak & 25 & 0,063 \\
\hline Nitrogen Total (sebagai N) & 50 & 0,125 \\
\hline pH paling & $2,5 \mathrm{~m} 2$ per ton produk minyak sawit (CPO) \\
\hline $\begin{array}{l}\text { Debit Limbah } \\
\text { Tinggi }\end{array}$
\end{tabular}

Sumber: Peraturan Menteri Lingkungan Hidup RI Nomor 5 Tahun 2014

Pada Tabel 1 dapat terlihat bahwa kadar BOD paling tinggi yang diperbolehkan adalah $100 \mathrm{mg} / \mathrm{L}$. Kadar COD paling tinggi yang diperbolehkan adalah $350 \mathrm{mg} / \mathrm{L}$. Jika hasil pengukuran BOD dan COD melebihi batas maksimal yang tertera pada Tabel 1, maka limbah cair tidak diperbolehkan dialirkan ke perairan bebas. Namun, jika nilai BOD dan COD berada dalam di bawah nilai tersebut, maka limbah cair aman untuk dialirkan atau dibuang ke perairan.

Setelah dari kolam 6, limbah dipompakan ke kolam 7, 8, dan 9 secara berurutan. Pada kolam 7, 8, dan 9 limbah diproses secara aerob. Tujuan pada proses ini adalah untuk mengubah limbah menjadi stabil dan tidak memberikan dampak pencemaran lingkungan dengan pemanfaatan aktivitas mikroba. Setelah dari kolam 9, limbah dipompakan ke kolam 10 untuk diendapkan kotorannya sebelum dibuang.

Berikut ini dijelaskan tentang kolam-kolam pengolahan limbah cair yang terdapat di PT. Tri Bakti Sarimas PKS 2 Ibul.

* Kolam Nomor 1 (Cooling Pond).

Kapasitas kolam ini adalah 8.208 $\mathrm{m}^{3}$, yang terdiri dari panjang $60 \mathrm{~m}$, lebar $30,4 \mathrm{~m}$, dan kedalaman $5 \mathrm{~m}$. Biasanya kolam hanya terisi 90\%. Kolam 1 ini merupakan tempat penampungan limbah 
yang pertama setelah keluar dari fat-fit. Kolam ini digunakan sebagai tempat pendinginan limbah cair yang baru datang dari pabrik. Umumnya limbah tersebut masih panas sekitar $50-70^{\circ} \mathrm{C}$ dan masih diperlakukan pendinginan sesuai dengan kondisi pengendalian limbah yang diinginkan bakteri. Pada proses ini, pendinginan bertujuan untuk mengurangi kadar minyak yang masuk ke dalam kolam pengasaman. Kelebihan konsentrasi minyak dapat menyebabkan kesulitan dalam mengoperasikan selanjutnya. Limbah cair di kolam pendinginan ini mempunyai karakteristik $\mathrm{pH} 4$ - 4,5 dengan suhu $60-80^{\circ} \mathrm{C}$. Sebelum dialirkan ke kolam selanjutnya, suhu limbah cair diturunkan menjadi 40$45^{\circ} \mathrm{C}$ agar bakteri mesofilik dapat berkembang dengan baik. Dengan temperaur $38^{\circ} \mathrm{C}$ maka bakteri akan berkembang biak dengan baik dengan rentang waktu selama \pm 5 hari. Kolam 1 atau Cooling Pond dapat dilihat pada Gambar 1.

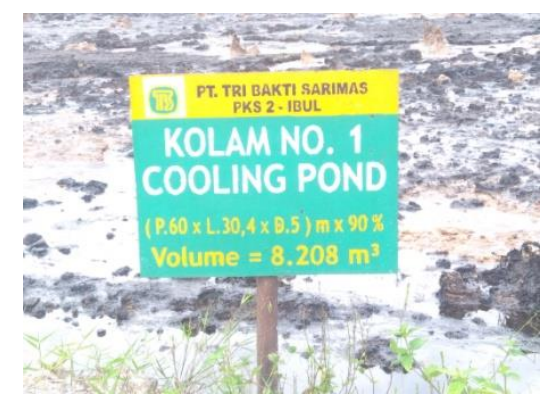

Gambar 1. Cooling Pond

* Kolam Nomor 2 (Anaerob Pond 1)

Kapasitas kolam ini adalah 22.752 $\mathrm{m}^{3}$, yang terdiri dari panjang $158 \mathrm{~m}$, lebar $32 \mathrm{~m}$ dan kedalaman $5 \mathrm{~m}$. Biasanya kolam hanya terisi 90\%. Limbah cair dari kolam satu dialirkan ke kolam 2 atau kolam anaerob. Kolam 2 ini merupakan tempat pengembang biakan bakteri mikroorganisme. BOD limbah setelah keluar dari kolam anaerob maksimal $350 \mathrm{mg} / \mathrm{L}$ dengan $\mathrm{pH} \quad 6,0$. Kolam anaerob 1 dapat dilihat pada Gambar 2.

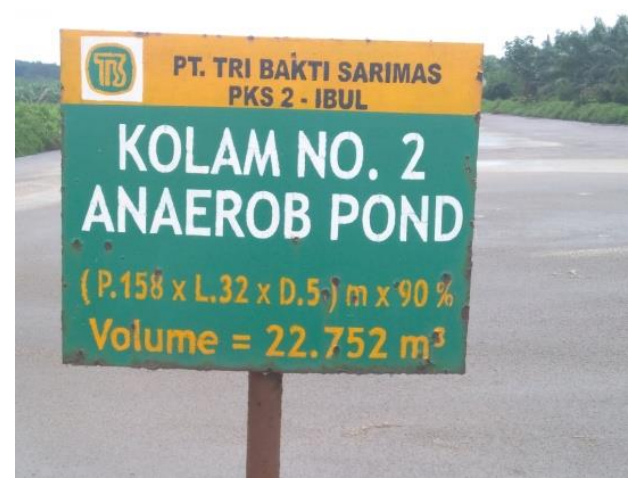

Gambar 2. Anaerob Pond

\section{* Kolam Nomor 3 (Anaerob Pond 2)}

Kapasitas kolam ini adalah 16.353 $\mathrm{m}^{3}$, yang terdiri dari panjang $158 \mathrm{~m}$, lebar $23 \mathrm{~m}$, dan kedalaman $5 \mathrm{~m}$. Biasanya kolam hanya terisi $90 \%$. Fungsi dari kolam ini sama dengan kolam 2 yakni untuk pengembangbiakan mikroorganisme. Kolam Anaerob 2 dapat dilihat pada Gambar 3.

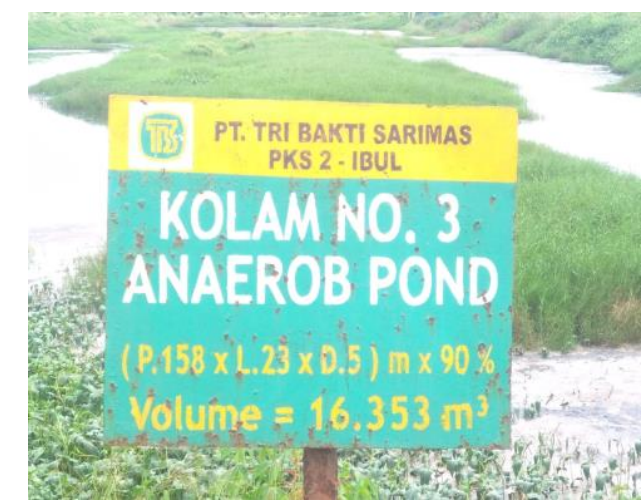

Gambar 3. Anaerob Pond 2

* Kolam Nomor 4 (Anaerob Pond 3)

Kapasitas kolam nomor 4 ini adalah $15.642 \mathrm{~m}^{3}$, yang terdiri dari panjang $158 \mathrm{~m}$, lebar $22 \mathrm{~m}$, dan kedalaman $5 \mathrm{~m}$. Biasanya kolam hanya terisi $90 \%$. Fungsi dari kolam ini sama dengan kolam 2 dan 3. Kolam Anaerob 3 dapat dilihat pada Gambar 4. 


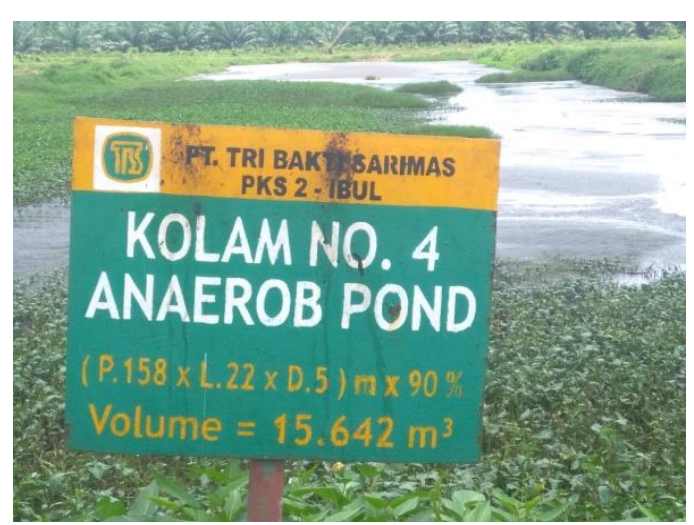

Gambar 4. Anaerob Pond 3

* Kolam Nomor 5 (Anaerob Pond 4)

Kapasitas kolam ini adalah 18.486 $\mathrm{m}^{3}$, yang terdiri dari panjang $158 \mathrm{~m}$, lebar $226 \mathrm{~m}$, dan kedalaman $5 \mathrm{~m}$. Biasanya kolam hanya terisi $90 \%$. Fungsi dari kolam 5 ini juga sama dengan kolam 2, 3, dan 4, yakni untuk pengembangbiakan mikroorganisme. Kolam Anaerob 4 dapat dilihat pada Gambar 5.

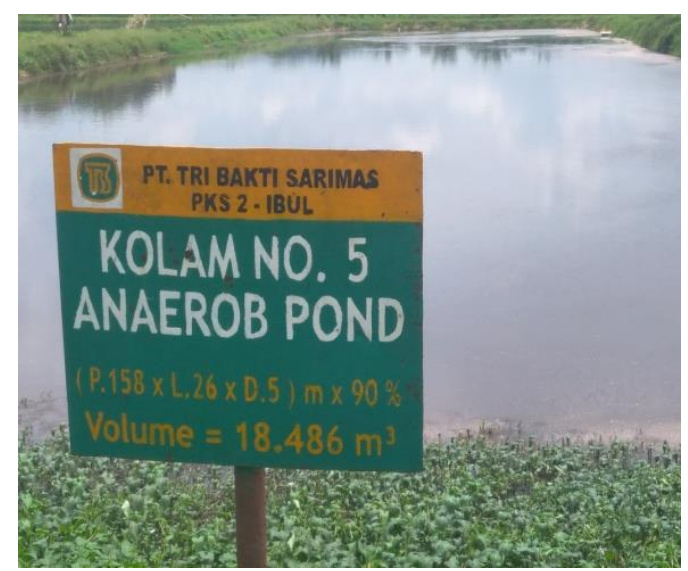

Gambar 5. Anaerob Pond 4

\section{\% Kolam Nomor 6 (Fakultatif Pond)}

Kapasitas kolam ini adalah $14.611,8 \mathrm{~m}^{3}$, dengan panjang $90,7 \mathrm{~m}$, lebar 35,8, dan kedalaman $5 \mathrm{~m}$. Biasanya kolam hanya terisi $90 \%$. Kolam fakultatif merupakan kolam stabilisasi antara kolam anaerob dengan kolam aerob. Waktu detensi pada kolam ini adalah 5 sampai 30 hari. Mekanisme kerja kolam fakultatif ini adalah: (1) Limbah organik difermentasi pertama kali di kolam anaerob dengan menambahkan lumpur aktif yang akan membantu proses degradasi limbah, dan (2) Efluen kemudian dialirkan pada kolam ini. Pada kolam ini mikroalga mulai banyak berperan sebagai agen Phycoremediasi. Ada dua jenis kolam fakultatif, yaitu: (1) Kolam Fakultatif Primer, yang menerima dan mengolah air limbah dari sumber pencemaran, dan (2) Kolam Fakultatif Sekunder, yang merupakan kolam anaerobik.

Pada kolam fakultatif, bahan anaerob diubah menjadi $\mathrm{CO}_{2}, \mathrm{H}_{2} \mathrm{O}$, serta bakteri dan alga baru. Hal tersebut dilakukan dalam suasana anaerob karena oksigen yang dihasilkan dari proses fotosintesis alga dimanfaatkan oleh bakteri anaerob untuk mendegradasi limbah anaerob lebih lanjut. Kolam ini juga berfungsi untuk mendegrdasi mikroorganisme penyebab penyakit. Kolam Fakultatif dapat dilihat pada Gambar 6.

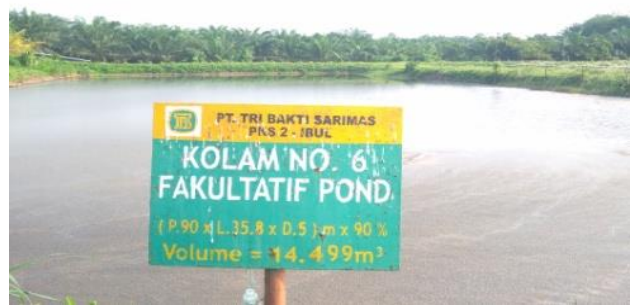

Gambar 6. Fakultatif Pond

\section{* Kolam Nomor 7 (Aerob Pond)}

Kapasitas kolam ini adalah 20.407 $\mathrm{m}^{3}$, dengan panjang $90,7 \mathrm{~m}$, lebar $50 \mathrm{~m}$, dan kedalaman $5 \mathrm{~m}$. Biasanya kolam ini hanya terisi $90 \%$. Pada kolam ini telah tumbuh gangang dan mikroba heterotrof yang berbentuk flocs. Pada kolam ini terjadi proses penyediaan oksigen yang dibutuhkan oleh mikroba dalam kolam. Di kolam ini terdapat alat aerator yang 
berfungsi sebagai alat untuk memasukan oksigen ke dalam kolam. Kolam Aerob dapat dilihat pada Gambar 7.

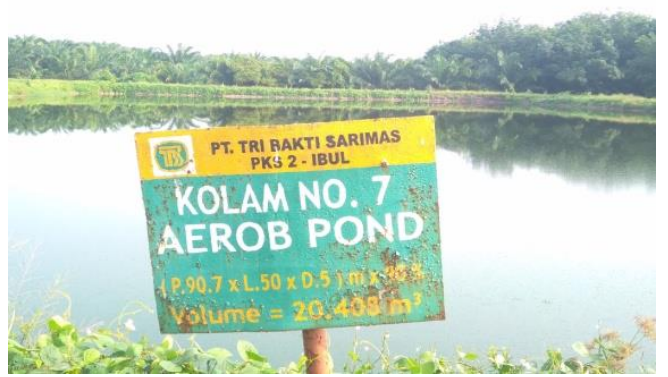

Gambar 7. Aerob Pond

* Kolam Nomor 8 (Aerob Pond)

Kapasitas kolam ini adalah 22.950 $\mathrm{m}^{3}$, yang terdiri dari panjang $102 \mathrm{~m}$, lebar $50 \mathrm{~m}$, dan kedalaman $5 \mathrm{~m}$. Biasanya kolam ini hanya terisi $90 \%$. Di kolam ini terjadi pemisahan bakteri dan unsur air sehingga bakteri pada limbah cair akan berkurang. Kolam Aerob dapat dilihat pada Gambar 8.

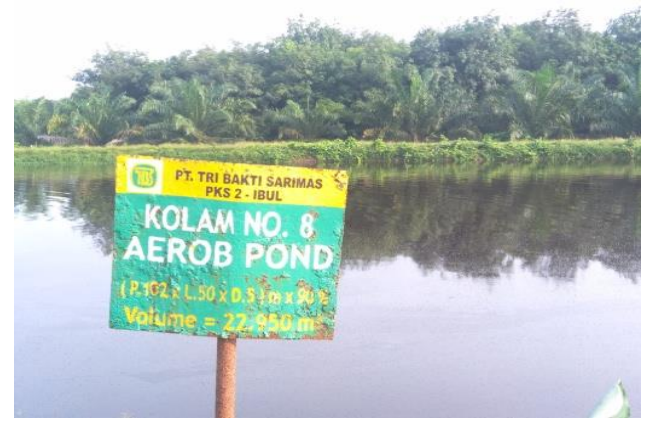

Gambar 8. Aerob Pond

क Kolam Nomor 9 (Aerob Pond)

Kapasitas kolam ini adalah $25.779,6 \mathrm{~m}^{3}$, yang terdiri dari panjang $184,8 \mathrm{~m}$, lebar $31 \mathrm{~m}$, dan kedalaman 5 m. Biasanya kola mini hanya terisi $90 \%$ saja. Fungsi dari kolam ini sama dengan kolam 8 yakni untuk pemisahan bakteri dari unsur air sehingga bakteri pada limbah cair menjadi berkurang.

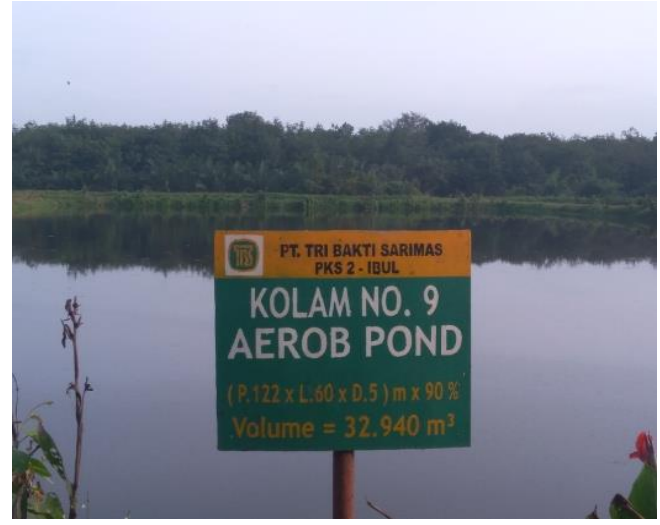

Gambar 9. Aerob Pond

\section{* Kolam Nomor 10 (Sediment Pond)}

Kapasitas kolam ini adalah $25.779,6 \mathrm{~m}^{3}$, yang terdiri dari panjang $184,8 \mathrm{~m}$, lebar $31 \mathrm{~m}$, dan kedalaman 5 m. Biasanya kolam ini hanya terisi $90 \%$ juga. Kolam ini merupakan kolam pengendapan lumpur dan unsur-unsur di dalam air. Kolam ini menghasilkan air agak sedikit jernih dan air limbah dapat dialirkan ke sungai (lingkungan), namun hasilnya harus sesuai dengan peraturan lingkungan. Kolam sedimentasi dapat dilihat pada Gambar 10.

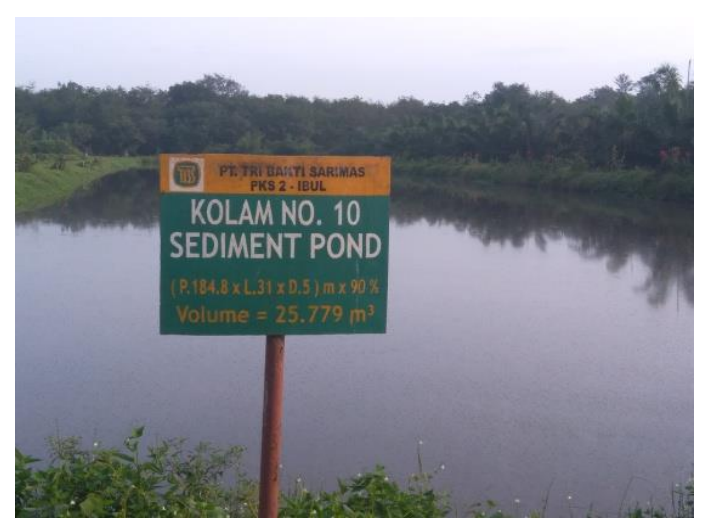

Gambar 10. Sediment Pond

\section{Uji Analisa COD (Chemical Oxygen Demand)}

COD (Chemical Oxygen Demand) merupakan jumlah oksigen yang dibutuhkan untuk mengoksidasi zat-zat organik yang ada pada limbah, seperti amonia dan nitrit. Semakin tinggi 
kadarnya menandakan kalau zat-zat tersebut masih dalam jumlah yang banyak dan berbahaya jika langsung diedarkan ke lingkungan. Maka di lakukan penurunan kadar COD agar tidak membahayakan lingkungan. Pengujian COD sangat diperlukan karena merupakan parameter dalam baku mutu air limbah. Hal ini menunjukkan bahwa COD dan juga BOD merupakan parameter dalam pencemaran perairan (Atima, 2015).

Sample yang diambil dibawa ke laboratorium untuk dilakukan pengujian. Pengujian sampel dilakukan dengan menggunakan alat COD Trak, Hasil pengujian menunjukkan hasil $319 \mathrm{mg} / \mathrm{L}$ COD. Berdasarkan baku mutu air limbah yang terdapat pada Tabel 1, dapat disimpulkan bahwa air limbah ini boleh dialirkan ke sungai, karena kadar paling tinggi COD yang diperbolehkan adalah $350 \mathrm{mg} / \mathrm{L}$. Alat untuk analisa COD dapat dilihat pada Gambar 11, sedangkan hasil pengujian dapat dilihat pada Gambar 12.

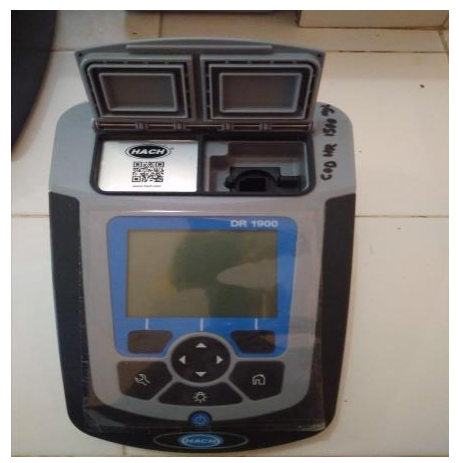

Gambar 11. COD Trak

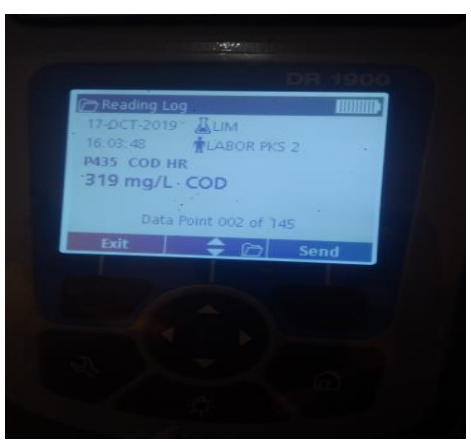

Gambar 12. Hasil Analisa COD

\section{Uji Analisa BOD (Biological Oxygen Demand)}

BOD (Biological Oxygen Demand) adalah parameter penduga jumlah oksigen yang dibutuhkan oleh bakteri untuk mengurai zat sisa yang ada pada limbah. BOD juga dapat menggambarkan kemampuan perairan dalam menguraikan bahan organik. Apabila kadar BOD pada limbah semakin tinggi, tetapi tetap dialirkan ke sungai maka hal itu dapat menyebabkan biota air mati. Hal ini disebabkan oleh asupan oksigen pada sungai akan diserap sepenuhnya oleh bakteri-bakteri yang ada untuk mendegradasi bahan-bahan organik (Atima, 2015). Oleh sebab itu, diperlukan pengujian analisa BOD sebelum limbah cair dialirkan ke sungai agar tidak merusak lingkungan.

Analisa pengujian dilakukan di laboratorium pada tanggal 17 Oktober 2019 pukul 16:03 WIB. Pengujian dilakukan dengan menggunakan alat BOD Trak, yang memerlukan waktu selama 5 hari. Didapatkan hasil nilai BOD sebesar $43 \mathrm{mg} / \mathrm{L}$. Berdasarkan Tabel 1 yang menunjukkan bahwa nilai tertinggi yang diperbolehkan untuk COD adalah $100 \mathrm{mg} / \mathrm{L}$, maka hasil ini menunjukkan bahwa limbah cair boleh di alirkan ke perairan bebas. Alat pengukuran COD dapat dilihat pada Gambar 13, sedangkan hasil pengukuran COD dapat dilihat pada Gambar 14.

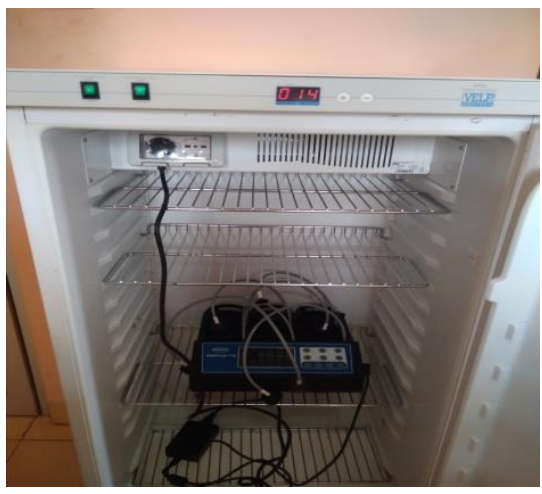

Gambar 13. BOD Trak 


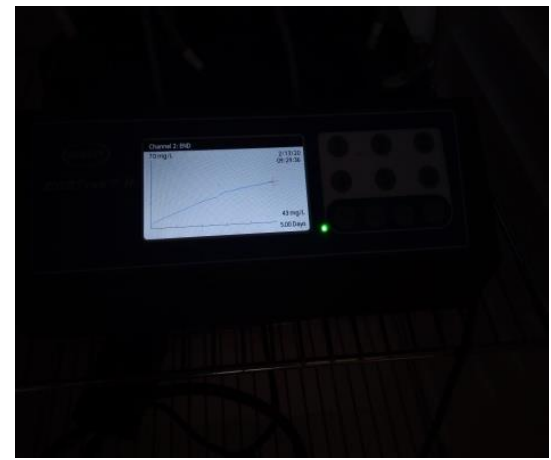

Gambar 14. Hasil Analisa BOD

\section{KESIMPULAN DAN SARAN}

\section{Kesimpulan}

Setelah mengamati pengolahan dan penanganan limbah cair di PT. Tri Bakti Sarimas PKS 2 Ibul maka dapat disimpulkan bahwa limbah yang dibuang harus memenuhi standar baku mutu limbah cair. Nilai maksimal yang diperbolehkan untuk COD adalah 350 $\mathrm{mg} / \mathrm{L}$, sedangkan untuk BOD adalah 100 $\mathrm{mg} / \mathrm{L}$. Dari data yang didapat di PT. Tri Bakti Sarimas PKS 2 Ibul untuk kadar COD dan BOD masing-masing 319 $\mathrm{mg} / \mathrm{L}$ dan $43 \mathrm{mg} / \mathrm{L}$ dan telah memenuhi syarat baku mutu limbah cair.

\section{Saran}

Saran yang pertama adalah untuk kolam limbah, perlu penambahan tanaman untuk menyerap zat yang berbahaya dan juga mengurangi erosi di sekitar kolam. Saran yang kedua adalah harus selalu menggunkan APD di lingkungan pabrik.

\section{DAFTAR PUSTAKA}

Atima, W. 2015. BOD dan COD sebagai Parameter Pencemaran Air dan Baku Mutu Air Limbah. Jurnal Biology Science \& Education, Vol. 4, No. 1. Hal: 83 -93.

Azahari, D.H. 2018. Sawit Indonesia yang Berkelanjutan, Tantangan dan Kebijakan yang Diperlukan. Ragam Pemikiran Menjawab Isu Aktual Pertanian. Jakarta: Penerbit IAARD Press.

BPS. 2020. Statistik Indonesia Statistical Yearbook of Indonesia 2020. Jakarta: Badan Pusat Statistik.

Nuraini, E., T. Fauziah, dan F. Lestari. 2019. Penentuan Nilai BOD dan COD Limbah Cair Inlet Laboratorium Pengujian Fisis Politeknik ATK Yogyakarta. Integrated Lab Journal, Vol. 07, No. 02. Hal: 10-15.

Peraturan Menteri Lingkungan Hidup Republik Indonesia Nomor 5 Tahun 2014.

Rachmawati, S.C. 2017. Analisa Penurunan Kadar COD dan BOD Limbah Cair Laboratorium Biokimia UIN Makasar Menggunakan Fly Ash (Abu Terbang) Batubara. Al- Kimia, Hal: 64-75.

Umaly, R. 1988. Limnology: Laboratory and Field Guide, PhysicoChemical Factors, Biological Factors. Metro Manila: National Book Store, Inc. 